\title{
A política monetária no Brasil e a atual retração do crédito
}

\author{
Rafael Camargo de Pauli*
}

RESUMO - Entre a execução da política monetária e seus resultados sobre os níveis de preços está o crédito. Há na literatura econômica um grande debate a respeito de como as disponibilidades de crédito são afetadas por uma política monetária contracionista. Alguns estudos $^{40}$ e dados disponíveis até julho deste ano sugerem que o canal de transmissão de crédito é pouco relevante no Brasil, isto é, aumentos nos juros não afetam as disponibilidades de empréstimos bancários, não afetando a inflação. Entretanto, acredita-se que o acirramento da crise financeira norte-americana pode vir a amplificar os efeitos deste mecanismo. Este artigo faz uma breve revisão da literatura a respeito dos canais de transmissão de política monetária com a intenção de verificar como o crédito pode ser afetado pelos recentes aumentos das taxas de juros em um contexto de crise financeira internacional.

Palavras-chave: Crédito. Política monetária. Crise norte-americana.

\section{INTRODUÇÃO}

Segundo Mishkin (1995, p. 4) "para ter sucesso na condução da política monetária, as autoridades (...) devem possuir uma sensibilidade acurada do tempo e dos efeitos das suas políticas sobre a economia." Dada a profunda instabilidade que paira sobre a economia mundial, mesmo para aqueles países que, como o Brasil, ainda não sofreram fortemente com a crise financeira americana, fica mais difícil crer nesta sensibilidade por parte dos bancos centrais

Alguns economistas apontam que o novo ciclo de aperto monetário é equivocado dadas as condições financeiras instáveis nos países desenvolvidos. Segundo o economista Bruno Rocha, em entrevista a Carvalho e Silva (Valor. 17/09/2008, p. C4) "a crise externa amplifica os efeitos de política monetária do Copom”. Pode-se argüir que, por um lado esta afirmação está correta, afinal as restrições de liquidez externa e o aumento dos juros domésticos inibem as decisões de investimento e de consumo de longo prazo. Por outro lado, entretanto, a crise tende a elevar a taxa de câmbio, como vem ocorrendo no Brasil, pressionando a elevação da inflação. Como exemplo disso, a recente decisão do Federal Reserve (Fed) de manter a taxa de juros americana em $2 \%$ ajudou a criar um fluxo de investimentos em direção aos Estados Unidos, o

\footnotetext{
* Mestrando em Desenvolvimento Econômico pelo Programa de Pós-Graduação em Desenvolvimento Econômico PPGDE da Universidade Federal do Paraná e supervisor geral do Boletim Economia \& Tecnologia. Endereço Eletrônico: rafaelcdp@gmail.com.

${ }^{40}$ Ver, por exemplo, Takeda (2003).
} 
que causou saída de capitais de alguns países emergentes, pressionando o câmbio destes. Portanto, a forma como a elevação da taxa Selic irá alvejar a inflação no Brasil está menos clara hoje do que em períodos anteriores de expansão dos juros.

O crédito, entretanto, tende a sofrer retração. Prova disto é a recente restrição de liquidez, que reduziu os empréstimos sindicalizados para o Brasil e tem restringido as linhas externas de financiamento ao comércio exterior. Com vistas a isto, o governo já tem se movido de modo a aumentar as disponibilidades de empréstimos por parte do BNDES, vislumbrando uma forte restrição do financiamento externo em 2009. A política monetária contracionista, no entanto, prossegue.

Neste sentido, para analisar o comportamento do mercado de crédito nacional na atual conjuntura internacional e frente ao novo ciclo de alta da taxa de juros é necessário analisar como os juros são conduzidos a fim de atingir as metas inflacionárias. A próxima seção apresenta uma descrição dos mecanismos de transmissão da política monetária para que, na seção seguinte, sejam analisados possíveis impactos no crédito. Esta abordagem é apropriada, uma vez que, como irá se constatar, alguns canais de transmissão, em especial o canal de crédito, afetam a disponibilidade de crédito de forma direta. A seção 3 mostra dados recentes da evolução do crédito no Brasil e a seção final conclui a discussão.

\section{OS CANAIS DE TRANSMISSÃO DA POLÍTICA MONETÁRIA}

Segundo Cecchetti (1999, p. 13) "todas as teorias de como mudanças nas taxas de juros afetam a economia começam em um ponto em comum: uma ação de política monetária” contracionista "começa com uma mudança no nível de reservas bancárias".

Ainda, alguns autores apontam que a taxa de juros não é a única responsável pela eficácia da política monetária. Bernake e Blinder (1992) e (1998), Bernanke (1993) e Li (2000) argumentam que a contração das reservas tem impactos sobre as decisões de empréstimos dos bancos, tanto para firmas como para as famílias.

Deste modo, para observar como a política monetária pode afetar o crédito, são expostos brevemente, a seguir, seus principais canais de transmissão, segundo a literatura.: o de juros, de câmbio, de preços dos ativos e de crédito.

\subsection{O CANAL DE JUROS}


Este canal se baseia na visão macroeconômica keynesiana. Nesta, os efeitos sobre o lado real da economia ocorrem como descritos no modelo IS-LM. O mecanismo pode ser resumido da seguinte maneira: o Banco Central realiza a contração monetária, via operações de mercado aberto com a emissão de títulos públicos, por exemplo. Com a menor quantidade de moeda disponível na economia, ocorre a elevação da taxa de juros de curtíssimo prazo; em conseqüência, assumindo a existência de rigidez de preços no curto prazo, as taxas de juros reais também se elevam. Como os retornos reais provenientes dos juros se tornam superiores à eficiência marginal do capital, ocorre redução do nível de investimento que, por sua vez, reduz a demanda agregada e reduz o produto. (MENDONÇA. 2001, p. 67)

Na prática, as operações de open market diminuem as reservas bancárias via emissão de títulos do tesouro nacional, os quais são adquiridos pelos bancos dealers. Estes bancos podem compor seus ativos com tais títulos, ou negociá-los com outros investidores direta ou indiretamente. A quantidade de moeda em circulação na economia é então reduzida, fazendo com que o preço por retê-la se torne mais alto, isto é, a taxa de juros aumenta. (CARVALHO et all. 2001, cap. 8)

$\mathrm{O}$ aumento das taxas de juros afeta as decisões de investimentos das firmas, sendo que as atividades menos rentáveis tendem a ser abandonadas. Ao reduzirem seus gastos em bens de consumo duráveis e em imóveis, em face do encarecimento do crédito, as famílias também afetam as decisões de investimento em determinados setores produtivos. O aumento da taxa de juros de curto prazo, no entanto, só surtirá efeito se os agentes acreditarem que as taxas de longo prazo também permanecerão elevadas por certo tempo. Portanto, a credibilidade do Banco Central é essencial para o timing do canal de juros.

\subsection{O CANAL DA TAXA DE CÂMBIO}

Com a abertura econômica promovida a partir da década de 1990 e a adoção do regime de banda cambial, o decorrente aumento da entrada de bens importados no mercado doméstico passou a influir fortemente nas taxas de inflação no Brasil. Esse mecanismo de controle inflacionário foi utilizado desde o início do plano Real, sendo abandonado após a desvalorização de 1999. Contudo, ele ainda é relevante no controle inflacionário e está fortemente relacionado ao aumento dos juros provocado pela política monetária. 
O argumento principal é o de que com o aumento das taxas de juros, os depósitos em moeda local se tornam mais atrativos do que depósitos em moedas de outros países. Isto acaba favorecendo a entrada de investimento estrangeiro direto e em carteira, pressionando a demanda por Reais, no caso do Brasil, causando sua valorização. Com isto, os produtos estrangeiros se tornam mais baratos internamente e os produtos nacionais se tornam mais caros para o resto do mundo, o que reduz as vendas das empresas instaladas no país, que, por sua vez, reduz o nível de atividade, reduzindo a demanda agregada e o produto da economia.

\subsection{O CANAL DE PREÇOS DOS ATIVOS}

Este canal se refere aos efeitos da política monetária sobre outros preços que não as taxas de juros e de câmbio, tais como preços de títulos, de ações e imóveis.

Particularmente, Mishkin (2001, p. 1) argumenta que os mecanismos de transmissão envolvendo o mercado de ações são de três tipos: i) efeitos no investimento; ii) efeito no balanço patrimonial das firmas, iii) efeito na riqueza das famílias e iv) efeito de liquidez das famílias.

O primeiro deles é apresentado pela análise do q de Tobin, constituído da razão entre o valor de mercado de uma empresa e o valor da reposição de seus ativos físicos, ou de maneira simplificada, seu valor contábil. Segundo Koch e Shenoy (1999) se a razão $q$ for maior que 1 significa que a empresa deve aproveitar um momento oportuno para uma nova oferta primária de ações. Isto é, se o valor de mercado de uma firma, dado pelo estoque de ações e títulos de dívida, é mais do que suficiente para repor todo seu estoque de capital físico, então o momento é propício para investimentos. Com um aumento das taxas de juros, as expectativas de ganhos com dividendos futuros por parte dos investidores será menor, podendo levá-los a sair dos mercados de ações, reduzindo os preços destas. Com isto o $q$ de Tobin tende cair abaixo de um, desestimulando a oferta de mais ações, ou seja, desestimulando o investimento e reduzindo a demanda agregada.

Já o efeito nos balanços das firmas está associado ao aumento do risco moral que uma política monetária contracionista promove. Com o aumento das taxas de juros, pode ocorrer deterioração da riqueza líquida das firmas, em face da queda nas suas vendas, com isto o crédito se torna mais difícil, o que as estimula a distorcer os riscos potenciais dos seus projetos, um resultado que leva os investidores a aumentar o prêmio de risco requerido para empréstimos. Cecchetti (1999) 
Ainda, segundo Mishkin (2001), o efeito sobre a riqueza das famílias é baseado no modelo de ciclo de vida de Modigliani. Nele, o consumo das famílias é determinado pelos recursos intertemporais destas. Considerando que as famílias carreguem quantias consideráveis de ações em suas carteiras de investimento, uma redução nos preços destas reduzirá seu consumo atual, promovendo queda no investimento.

Já o efeito de liquidez se refere à preferência pela liquidez por parte das famílias. Caso elas considerem que as ações estão pouco líquidas, reduzirão o consumo de bens duráveis e imóveis, de modo a recuperar liquidez em suas carteiras de ativos. Mishkin (2001).

\subsection{O CANAL DE CRÉDITO}

De acordo com Bernanke e Gertler (1995, p. 29), o canal de crédito ocorre através do aumento do prêmio de financiamento externo ${ }^{41}$, em face de um acréscimo nas taxas de juros domésticas. Isso se dá a partir de dois mecanismos: o canal de balanços patrimoniais das firmas e o canal de empréstimos bancários. O primeiro deles surge, pois aumentos nas taxas de juros aumentam os gastos com juros por parte das empresas, reduzindo suas disponibilidades de caixa e enfraquecendo suas posições financeiras. Além disso, com juros mais altos os preços das ações caem, o que reduz o valor do colateral das firmas ${ }^{42}$.

O canal de empréstimos bancários ocorre, por sua vez, partindo-se do princípio de que os bancos são especializados em superar os problemas de informação assimétrica e se utilizam das melhores fontes de intermediação de crédito na maioria das economias. Se a oferta de empréstimos bancários é reduzida por retração de liquidez, as firmas dependentes destes, normalmente de médio ou pequeno porte, irão observar aumentos nos seus custos ao procurar novos credores e estabelecer uma nova relação de crédito com estes. "Portanto, uma redução na oferta de crédito bancário, relativa a outras formas de crédito, pode aumentar o prêmio de financiamento externo e reduzir o nível de atividade.” (BERNANKE E GERTLER. 1995, p. 40).

Já Denardin e Neto (2008, p. 2) explicam o canal de empréstimos bancários da seguinte maneira:

\footnotetext{
${ }^{41}$ Diferença entre os custos dos fundos captados externamente e daqueles captados internamente (BERNANKE e GERTLER. 1995, p. 3)

42 Observe-se na seção 2.3 que este efeito é, para Mishkin (2001), classificado no canal de preços dos ativos. A diferença é a de que o canal de balanços das firmas descrito por Bernanke e Gertler é mais abrangente, levando em consideração não só os preços dos ativos, mas também o fluxo de caixa das firmas, como determinantes das suas posições financeiras.
} 
Tem- se como principal argumento que a oferta de empréstimos bancários depende dos depósitos, assim sendo, ao afetar o lado passivo do balanço patrimonial dos bancos, comprometendo o volume de depósitos, a política monetária afeta também o lado do ativo do balanço bancário. Ao comprometer a habilidade dos bancos em gerar empréstimos, a política monetária acaba interferindo nas decisões de gastos dos agentes (tomadores de empréstimos) que são dependentes dos bancos e, consequentemente, na atividade produtiva, contribuindo, deste modo, para potencializar os efeitos de choques monetários sobre o setor real da economia.

Observa-se que o canal de crédito parece explicar melhor a retração de crédito frente a um aumento dos juros. A seção seguinte se destina a analisar a oferta de crédito e suas relações com a taxa de juros. Inicialmente são expostos os resultados de expansões anteriores e, em seguida, estes são comparados com o ciclo de contração monetária atual.

\section{AUMENTOS DOS JUROS NO BRASIL E SEUS EFEITOS SOBRE O CRÉDITO}

A partir da exposição acima, pode-se ter referência de como o crédito se comportaria com os anúncios de aumentos das taxas de juros básicas por parte do Banco Central do Brasil.

De acordo com o canal de crédito via balanços patrimoniais é de se esperar que tais anúncios sejam seguidos por quedas nos preços das ações das empresas e em seus fluxos de caixa líquidos. O gráfico abaixo demonstra a evolução recente de dois indicadores das bolsas de valores de São Paulo, o Ibovespa e o Índice do Setor Industrial (INDX), que é composto por empresas ligadas à indústria e, portanto, tende a excluir o efeito DIRETO das grandes empresas que afetam o Ibovespa: Petrobras e Companhia Vale do Rio Doce.

\section{GRÁFICO 1 - IBOVESPA E INDICE DO SETOR INDUSTRIAL INDX - 2008}

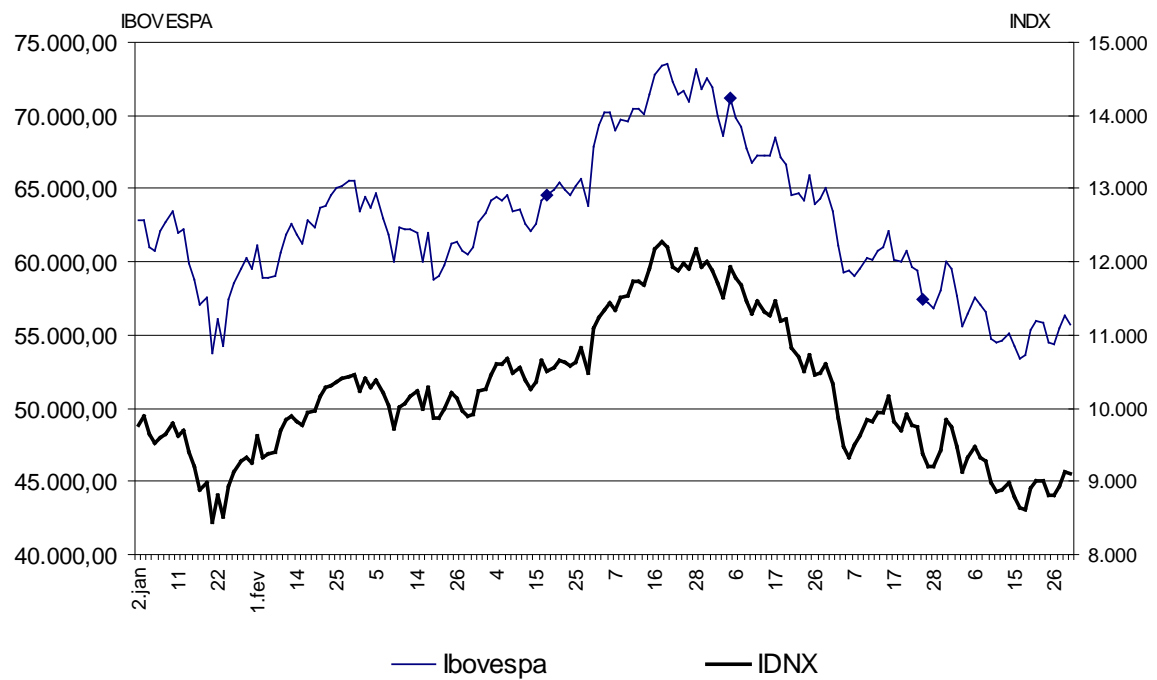

FONTE: Elaboração própria a partir de dados da BOVESPA e SGS (Banco Central do Brasil). 
Observa-se que as datas nas quais a meta da taxa Selic foi aumentada (com marcadores na série Ibovespa) são seguidas de quedas nos indicadores acionários Ibovespa e INDX, com exceção do primeiro acréscimo, em 17 de abril, cujo aumento foi o menor do novo ciclo, 0,5 pontos percentuais.

Portanto, o atual ciclo de aumento das taxas de juros está sendo acompanhado pela queda do mercado acionário. Isto está de acordo com a teoria apresentada na seção 2.4, mas as causas para tal evento, como sugerem os dois ciclos anteriores descritos no gráfico abaixo, não são os aumentos dos juros.

O gráfico 2 mostra que o Ibovespa foi pouco sensível aos aumentos das taxas de juros nos dois últimos ciclos de aperto monetário. Entre 15/10/2002 e 18/06/2003, período em que a meta da taxa Selic aumentou 5,5 pontos percentuais, o índice da bolsa de valores de São Paulo apresentou acréscimo de 58,8\%. Entre 16/09/2004 e 15/09/2005, quanto a Selic subiu de 16\% para 19,5\% ao ano, o Ibovespa cresceu 30\%. Isto sugere que empresas com capital aberto, em geral, não observaram queda nos preços de suas ações e, portanto, não registraram piora em suas posições financeiras pelo canal de balanço patrimonial.

GRÁFICO 2 - IBOVESPA E METAS DA TAXA SELIC - 2002- 2008

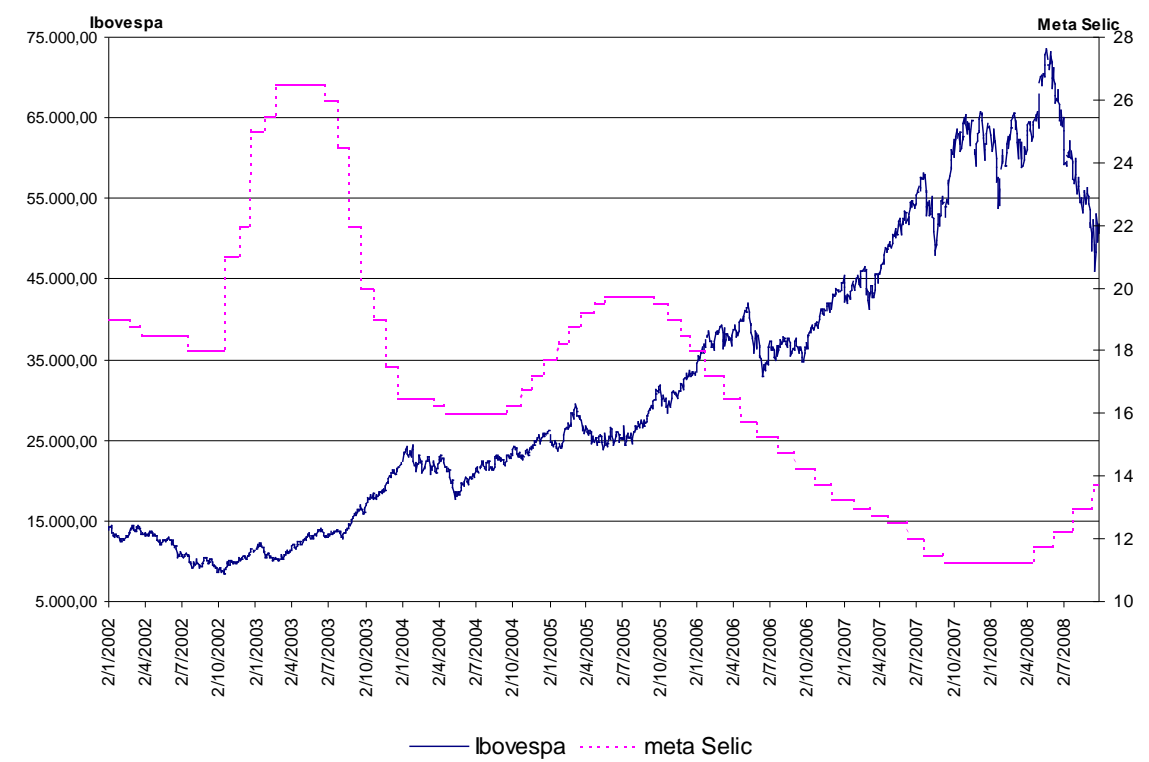

FONTE: Elaboração própria com dados da BOVESPA e COPOM (SGS/Banco Central do Brasil).

Isto leva crer que, embora o canal crédito via balanços patrimoniais das empresas não tenha sido significativo em períodos anteriores de política monetária contracionista, ele pode vir a 
amplificar as restrições de crédito no ciclo atual para empresas que sofrerem perdas significativas em seus valores de mercado.

Agora, de modo a verificar o canal de empréstimos dos bancos, expõem-se abaixo dados recentes sobre as operações de crédito do sistema financeiro nacional.

\section{GRÁFICO 3 - CARTEIRA DE ATIVOS DOS BANCOS EM OPERAÇÕES DE CRÉDITO PARA PESSOAS} JURÍDICAS REFERENCIAIS PARA TAXA DE JUROS - DEZ/2006 - AGO/2008

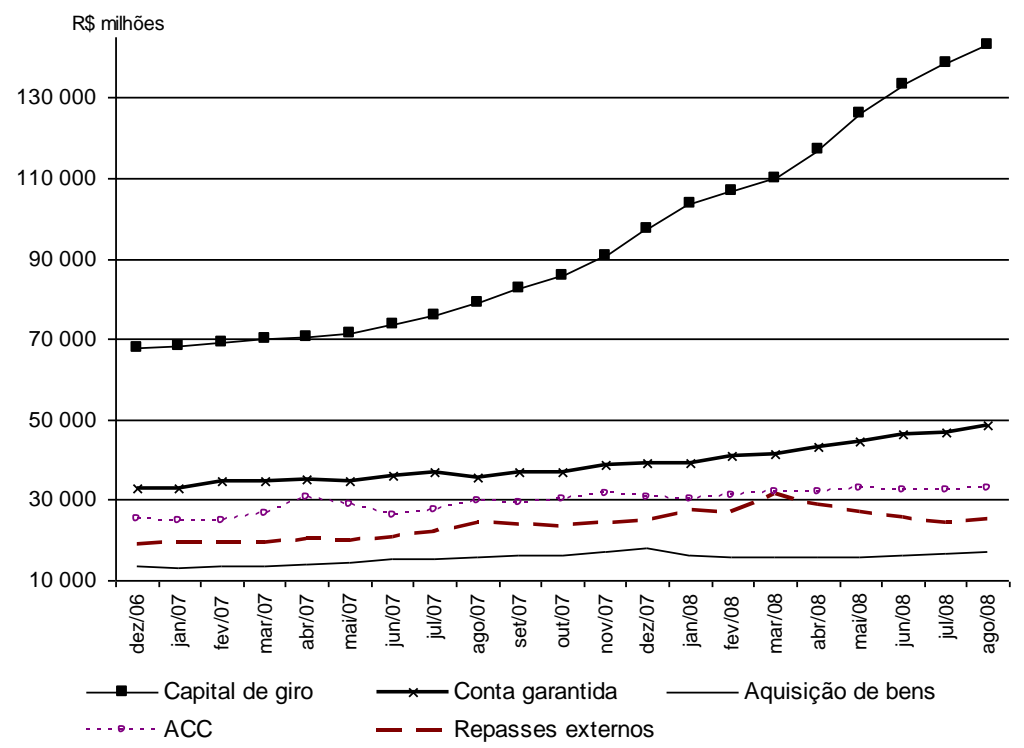

FONTE: Elaboração própria com os dados do Boletim mensal do BACEN e PASCS10/Sisbacen para o mês de agosto de 2008 .

Observa-se que as principais operações de crédito para pessoas jurídicas não sofreram alterações significativas em suas tendências até agosto deste ano, com a exceção de repasses externos, que passaram a apresentar queda a partir de abril. Destacam-se as operações de crédito para capital de giro que aumentaram 34\% entre janeiro e julho de 2008. As operações para pessoas físicas também se mostraram estáveis. Ao todo, esta modalidade subiu 8,1\% de janeiro a julho de 2008. Em mesmo período de 2007, entretanto, a expansão foi de 13\%. Isso pode estar indicando que o aumento dos juros associados à crise financeira estão reduzindo as disponibilidades de crédito.

\section{CONCLUSÃO}

A partir da comparação dos dados empíricos disponíveis ${ }^{43}$ com a literatura abordada sobre os mecanismos de impactos ao crédito, pode-se concluir que os aumentos das taxas de

\footnotetext{
${ }^{43}$ Até a redação deste artigo não se encontraram disponíveis os dados referentes a setembro.
} 
juros não têm afetado substancialmente a oferta de crédito por parte dos bancos no Brasil. No entanto, acredita-se que as tendências apresentadas no gráfico 2 mudaram em setembro, devido ao acirramento da crise de liquidez nos países desenvolvidos.

Neste sentido, a retração do crédito em nível mundial tenderia a agir tal como o canal de crédito opera (segundo a teoria econômica dos canais de transmissão dos juros) sobre a liquidez da economia brasileira. Os efeitos sobre a inflação, no curto prazo, não são evidentes, uma vez que recentemente o canal da taxa de câmbio pressiona sua alta. Já os efeitos sobre o crédito são, inevitavelmente, negativos. Cabe ao Banco Central amenizar os efeitos da crise promovendo maior liquidez ao sistema financeiro.

\section{REFERÊNCIAS}

BERNANKE, B. S.; (2000). Credit in the Macroeconomy. Federal Reserve Bank of New York Quaterly Review.

BERNAKE, B. S.; BLINDER, A. S.; (1989). Credit, Money, and Aggregate Demand. The American Economic Review, Vol. 78, No. 2. pp. 435-439. Disponível em: http://www.jstor.org/ stable/1818164. Acesso em: 10/09/2008.

; (1992). The Federal Funds Rate and the Channels of Monetary

Transmission. The American Economic Review, Volume 82, Issue 4. Disponível em: http://www.sbeusers.csuhayward.edu/ alima/COURSES/4315/Week05/

BlinderBernankeChan nelsTransmission.pdf. Acesso em: 10/08/2008.

Boletim do Banco Central - Relatório Mensal. Brasília: Banco Central do Brasil. Disponível em: http://www.bcb.gov.br/?BOLETIMEST. Acesso em: 22/09/2008.

CARVALHO, C. C.; JUNIOR, A. S. Crédito a eletroeletrônicos e veículos deve escassear. Valor Econômico. São Paulo, 17 set. 2008. Finanças, p. C4.

CARVALHO, F. C.; et all. (2001). Economia Monetária e Financeira. Rio de Janeiro. Campus. Ed. 1.

CECCHETTI, G. S.; (1999). Legal Structure, Financial Structure, and the Monetary Policy Transmission Mechanism. FRBNY Economic Policy Review. Disponível em: http:/ / people.brandeis.edu/ cecchett/pdf/epr799.pdf. Acesso em: 10/08/2008.

DENARDIN, A. A.; NETO, G. B.; (2008). O mecanismo de transmissão da política monetária: evidências empíricas para o canal do empréstimo bancário no Brasil. XI Encontro Regional de Economia da Região Sul - AnpecSul- 2008. Acesso em: 
http://www.boletim deconjuntura.ufpr.br/XI_ANPEC-Sul/artigos_pdf/a3/ANPEC-Sul-A3-14o_mecanismo_de_transmiss.pdf. Acesso em: 20/09/2008.

Evolução Diária - Ibovespa e INDX. São Paulo: Bolsa de Valores de São Paulo. Disponível em: http://www.bovespa.com.br/Principal.asp. Acesso em: 30/09/2008.

KOCH, P. D.; SHENOY, C. (1999). The information content of dividend and capital structure policies. http://www2.business.ku.edu/pkoch/documents/Div-Lev.pdf). Acesso em: 10/09/2008.

LI, V. E.; (2000). Household Credit and Transmission Mechanism. Journal of money, Banking, and Credit (32)3.

MENDONÇA, H. F.; (2001). Mecanismos de transmissão monetária e a determinação da taxa de juros: uma aplicação da regra de Taylor. Economia e Sociedade (16): 65-81. Disponível em: http://www.face.ufmg.br/daface/aulas/marcello/Taylor.doc. Acesso em: 10/09/2008.

MISHKIN, F. S.; (1995). Symposium on the Monetary Transmission Mechanism. The Journal of Economic Perspectives. Vol. 9 n. 4. Disponível em: http://www.jstor.org/sici?sici = 0895-3309(199523)9\%3A4\%3C3\%3A\%22OTMTM\% 3E2.0.CO;2-T. Acesso em: 10/08/2008.

MISHKIN, F. S.; (2001),_The Transmission Mechanism and the Role of Asset Prices in Monetary Policy. Disponível em: http://www2.gsb.columbia.edu/ faculty/fmishkin/ PDFpapers/w8617.pdf. Acesso em: 10/09/2008.

Sistema Gerenciador de Séries Temporais. Taxa de juros - Meta Selic definida pelo Copom. Brasília: Banco Central do Brasil. Disponível em: https://www3.bcb.gov.br/sgspub/ consultarvalores/telaCvsSelecionarSeries.paint. Acesso em: 22/09/2008.

TAKEDA, T.; (2003). Efeitos da Política Monetária sobre a Oferta de Crédito. Disponível em: $\quad$ www.bcb.gov.br/Pec/SeminarioEcoBanCre/Port/X\%20-\%20Efeitos $\% 20 \quad$ PolMonetária\%20-\%204JSB.pdf. Acesso em: 10/08/2008. 